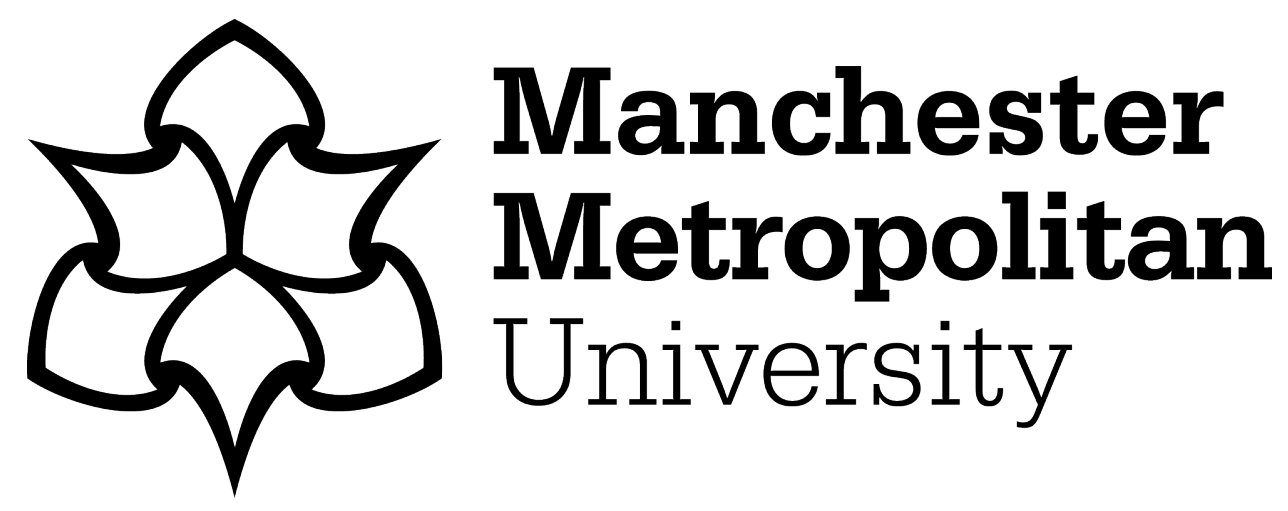

Fatoye, Clara Toyin, Gebrye, Tadesse ORCID logoORCID: https://orcid.org/0000-0001-7976-2013 and Fatoye, Francis ORCID logoORCID: https://orcid.org/0000-0002-3502-3953 (2022) The Effectiveness of Personalisation on Health Outcomes of Older People: Systematic Review. Research on Social Work Practice, 32 (2). pp. 146-154. ISSN 1049-7315

Downloaded from: https://e-space.mmu.ac.uk/628656/

Version: Published Version

Publisher: SAGE Publications

DOI: https://doi.org/10.1177/10497315211051629

Usage rights: Creative Commons: Attribution-Noncommercial 4.0

Please cite the published version 


\title{
The Effectiveness of Personalisation on Health Outcomes of Older People: A Systematic Review
}

Research on Social Work Practice 202I, Vol. 0(0) I-9

(C) The Author(s) 2021

(c) (i) (8)

Article reuse guidelines: sagepub.com/journals-permissions DOI: $10.1177 / 10497315211051629$ journals.sagepub.com/home/rsw @SAGE

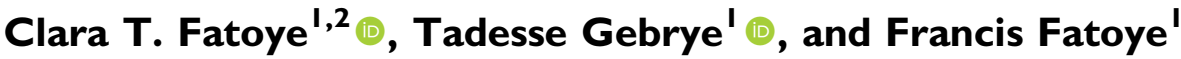

\begin{abstract}
Purpose: As people get older, they tend to have long-term conditions requiring health and social care intervention such as personalisation. Personalisation is person centred ensuring independence and control. To date, no systematic review has examined the effectiveness of personalisation. This review examined the effectiveness of personalisation in older people.
\end{abstract}

Methods: A systematic review following Preferred Reporting Items for Systematic Reviews and Meta-Analyses guidelines was undertaken. Databases searched included: Science Direct and Medline (PubMed) NHSEED and CINAHL. Inclusion criteria were older people living in their own homes receiving personalisation. Excluded were studies carried out in nursing homes. Newcastle-Ottawa Scale was used for quality of assessment.

Results: Search yielded I5I published studies with titles and abstracts; I43 studies were excluded and eight included. Studies included showed health outcomes of older people receiving personalisation improved significantly.

Conclusions: Review found evidence of improvement in quality of life and mobility in older people.

The purpose of this paper was to know if personalisation or homecare is effective in improving the health outcome of older people. It simply compared interventions for older people in the comfort of their own homes and in an institutional home. The United Nations have used measures and indicator of population ageing mostly based on people's chronological age, defining older person as those aged from 60 or over. This helps to provide a simple, clear and easy replicable way to measure and track various indicators of ageing population (Nations, 2019).

Most people are expected to live into their sixties and beyond, there are 434 million people in this age group worldwide (WHO, 2018). Ageing population around the world is increasing dramatically. Hence, the shift in distribution of population towards older age known as ageing population. A longer life brings with it opportunities of additional years for older people, their families and the society as a whole. Additional years provide the chance to pursue new activities such as further education, a new career or pursuing a long-neglected passion. However, the extent to which they can contribute depends heavily on their health. If older people experience decline in physical and mental capacity, then the implications for older people, their families and the society at large would be negative (WHO, 2018).

As people get older, they tend to have long-term health conditions such as hearing loss, cataracts, back and neck pain or osteoarthritis, chronic pulmonary diseases. Diabetes, depression and dementia and other conditions not categories under the disease category but they are common in older people such as frailty, urinary incontinence, falls, delirium and pressure ulcers (WHO, 2018). These conditions require health and social care intervention such as personalisation, where older people are supported with their needs in the comfort of their homes (Glendinning, Mitchell, \& Brooks, 2015).

During the year 2019, more than one fifth (20.3\%) of the European population was aged 65 and over (Eurostat, 2017). The global population aged 60 years or over were numbered 962 million in 2017, more than twice as large as in 1980 when there were 382 million older persons worldwide (Feigin et al., 2017). The number of older persons expected to double again by 2050 , when it is projected to reach nearly 2.1 billion (Lutz, Butz, \& Samir, 2017). A total of $23 \%$ of global burden of disease was attributed to disorders in people aged 60 years and older (Prince et al., 2015).

\footnotetext{
'Department of Health Professions, Manchester Metropolitan University, Manchester, UK

${ }^{2}$ University Campus Oldham, Oldham, UK

Corresponding Author:

Clara Fatoye, Department of Health and Social Care, University campus Oldham (UCO), 53 Bonsall Street, Manchester MI5 6GX, UK.

Email: clara.fatoye@oldham.ac.uk
} 
According to Barnett and colleagues, $75 \%$ of 75 year-olds in the UK have more than one long-term condition, which can make them to start finding daily living tasks more difficult (2010). Older people are to be supported to remain healthy and independent in their homes for as long as possible with their needs, one of the ways to do this is through personalisation.

Personalisation as a social care approach indicate that everybody in the community who is receiving support either provided by their local authorities or privately funded should have a choice over their care known as consumer-directed care in America and should have flexibility in terms of accessing services irrespective of the care setting (DH, 2010a). Personalisation is often associated with personal budgets and direct payments where service users can request for the type of services that they need. Giving room for them to choose from options of services unlike institutional care services provided by local authorities where they are not allowed to choose the type of services that they need (DH, 2010b; Lakey \& Saunders, 2011).

Personalisation should be practiced with effective information provision regarding care and support for individuals and families receiving personalisation thereby promoting independence and self-reliance among these individuals and the community (Irvine, F., Wah Yeung, E. Y., Partridge, M., \& Simcock., 2017). The best way to test the success of personalisation is to examine the extent or the ways it has improved the lives of the people using it often refer to as clients or service users (Leadbeater, 2004). Personalisation is very important for older people especially those who live alone to give them the help that is provided through personalisation. Other people that may benefit from personalisation are the groups marginalised such as people from black and minority ethnic groups, and lesbian, gay, bisexual and transgender (LGBT) community (Cyrus, 2017). People with substance misuse, people with learning difficulties, refugees and asylum seekers and people who live in rural areas (Glasby and Dickinson, 2014). The present and previous government in England seek to transform adult social care by introducing personal budgets to achieve better personalisation of care and support (Zamfir, 2013).

There is evidence to suggest that the number of older people with dementia benefiting from personalisation is unacceptably low (Lakey \& Saunders, 2011). In order to raise this level, it was suggested that all barriers to uptake of personalisation must be removed. This is to ensure that more people in need of help such as people with dementia could benefit through being given the options of personalisation. This could be done through providing better information needed to make their own choice about their care (Lakey \& Saunders, 2011).

According to a study by Foster, Harris, Jackson, Morgan, and Glendinning, (2006), health and social care services providers or practitioners are to meet the needs of older people through personalisation including those with complex health and social care needs. Lloyd, (2010) suggested that personalisation should be person-centred and should focus on the person using the service, provide quality care, and able to meet assessed needs of the service user. Meeting the quality standard acceptable for both service user and their careers and lastly support in place through personalisation should be such that it would benefit unpaid carers ensuring holistic support is provided.

To the knowledge of the authors, this is the first systematic review that explored the effectiveness of personalisation with older people. Although previous studies have examined the effectiveness of personalisation, some included real world data, they were not assessed for quality as was carried out by this review.

\section{Method}

\section{Search Protocol and Registration}

The purpose of this paper is to know if personalisation or homecare is effective in improving the health outcome of older people. It is simply comparing intervention for older people in the comfort of their own homes and in an institutional home to know which one is effective. This research aim guided the selection of the databases and the keywords that have been used in this study.

A systematic review following the Preferred Reporting Items for Systematic Reviews and Meta-Analyses (PRISMA) was used for this study. Systematic reviews and meta-analyses have become increasingly important in health care; it addresses the data sources, eligibility, data extraction and data analysis as guidance for reporting (Moher, Liberati, Tetzlaff, \& Altman, \& Prisma Group, 2009, 2015). This review was registered on PROPERO with registration number: CRD42019157155

\section{Data Sources}

The following search terms were run on MEDLINE, (PubMed), NHS EED and CINAHL between 2010 and 2021. The search terms used were effect, effectiveness, impact, efficacy, health, outcome, health outcome, health benefit, personalisation, direct payment, caring at home, home care, community care, shelter living, domiciliary care, older people, adult, elderly, elderly people, quality of life, pain, and depression and anxiety. These search terms were combined using conjunctions such as 'AND' and 'OR'. Two reviewers (CF and TG) participated in the search of literatures. Search results were limited to the English language, abstract available and published in the last 10 years as personalisation was introduced around the time. Studies included were those that compared the effectiveness of personalisation to institutional care and lastly, they were also studies conducted in older people Both reviewers independently screened the full articles against the inclusion and exclusion criteria; any disagreements between the two reviewers were resolved by consultation with the third reviewer (FF). 


\section{Risk of Bias Assessment}

Once the eligible studies were finalised, the quality of studies was appraised by two reviewers (CF and $\mathrm{TG}$ ) using the Newcastle-Ottawa scale (NOS). Newcastle-Ottawa Scale is used for the assessment of quality of studies included and a quality of risk of bias assessment. According to Wells et al., (2000), the NOS is used for assessing the quality of studies with its design, content and incorporating the quality assessments in the interpretation of meta-analytic results. A 'star system' has been developed to judge a study on three broad perspectives as follows: the selection of the study groups; the comparability of the groups and the ascertainment of either the exposure or outcome of interest for case-control or cohort studies, respectively. This has provided a convenient justification tool for quality assessment of nonrandomised studies to be used in a systematic review (Table 1).

\section{Data Extraction and Analysis}

A narrative synthesis was used to analyse the extracted results from the included studies. Two researchers (CF and TG) independently extracted data. When there was disagreement between the researchers a third researcher (FF) was consulted. Data extracted on parameters included names of authors, year of publications, number of participants, age of participants, study location, type of intervention, duration of intervention, comparator and outcome measures. Findings from these studies are presented as a summery in Table 2 by outcomes of the effectiveness of personalisation.

\section{Results}

We identified 151 records through the search strategy, and 128 of these were excluded based on the pre-specified inclusion and exclusion criteria (Figure 1). A total of 23 articles were considered for full text reading, and only eight articles were included in the review.

\section{Methodological Quality}

The quality of the included studies was rated between seven and 8 (NOS) (Table 3). Two of the included studies either did not report a follow-up long enough for outcomes to occur or adequacy of follow up of cohorts.

\section{General Characteristics}

The general characteristics of the included studies are presented in Table 2. The eight included studies were conducted in Austria (Klug et al., 2010), Australia (Spink et al., 2011), Germany (Jocham, H. R., Dassen, T., Widdershoven, G., Middel, B., \& Halfens, 2009), Iran (Mehralian, Salehi, Moghaddasi, Amiri, \& Rafiei, 2014), Japan (Aoki et al., 2015), Sweden (Zidén, Kreuter, \& Frändin, 2010) and Turkey (Yumin et al., 2011; Bilgin \& Gozum, 2018). The mean sample size of the included studies was 140 (range 60-305 patients). The mean age of patients was $\geq 63$ years. Out of the studies included, four were RCTs (Klug et al., 2010; Spink et al., 2011; Zidén et al., 2010; Mehralian et al., 2014), one was quasi-experiment (Yümin, Șimșek, Sertel, Öztürk, \& Yümin, 2011), one was a longitudinal observational study (Jocham et al., 2009) and one was a pre-test, post-test-controlled model (Bilgin \& Gozum, 2018). The interventions were provided by professionals such as psychiatrist (Klug et al., 2010), social workers (Klug et al., 2010), podiatrist (Spink et al., 2011), Nurses (Mehralian et al., 2014; Bilgin \& Gozum, 2018), psychologist (Klug et al., 2010) or physiotherapist (Zidén et al., 2010; Aoki et al., 2015).

\section{Effectiveness of Intervention}

Evidence on the effectiveness of various types of personalisation interventions on the health outcomes of elderly people is presented in Table (2). One study (Klug et al., 2010) reported fewer symptoms of depressions. Klug and colleague found that home treatment reduced major depression (2010). Older people who received home care had Improved healthrelated quality of life (Yümin et al., 2011; Bilgin \& Gozum, 2018; Aoki et al., 2015; Mehralian et al., 2014). Further, as a result of the intervention improved functional mobility (Yümin et al., 2011; Aoki et al., 2015), fewer falls (Spink et al., 2011), improved degree of independence (Zidén et al., 2010) and improved emotional cognitive functions (Bilgin \& Gozum, 2018) were reported by the studies included in the review. Overall, except in one study (Jocham et al., 2009) all included studies showed that personalisation improved the health outcomes of older.

The study demonstrated that personalisation resulted in clinical benefits for older people (Yümin et al., 2011; Bilgin \& Gozum, 2018; Aoki et al., 2015; Mehralian et al., 2014). This

Table I. Eligibility Criteria (Inclusion and Exclusion Criteria).

\begin{tabular}{ll}
\hline Inclusion & Exclusion \\
\hline Any study on older people at home from the age of 55 years & Studies done in nursing home/institutions \\
Studies conducted in English & Studies not conducted in English \\
& Studies conducted with people less than 55 years
\end{tabular}

Studies compared with any type of intervention such as standard of care or no intervention

Studies conducted from 2010 to 2021 


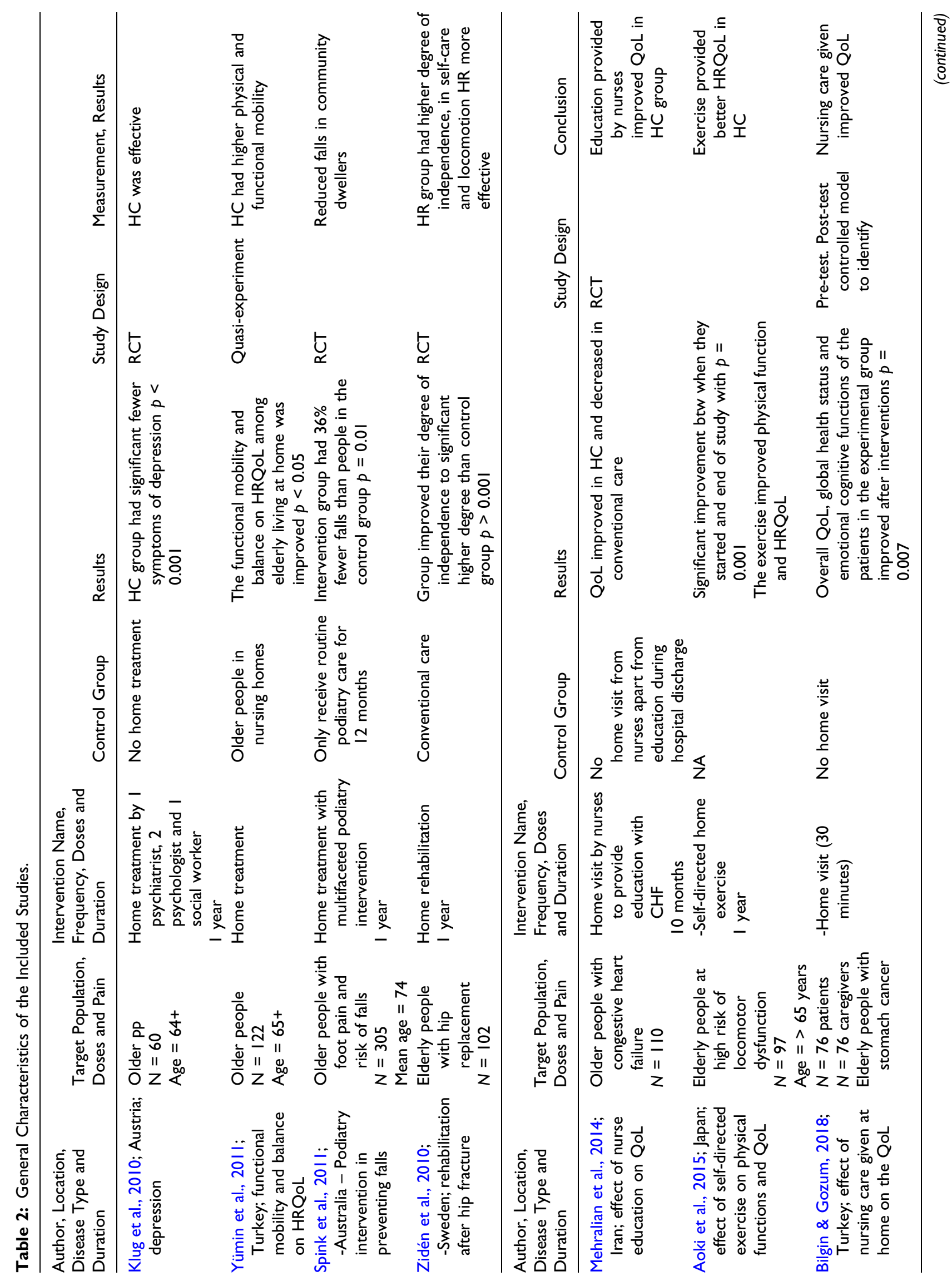




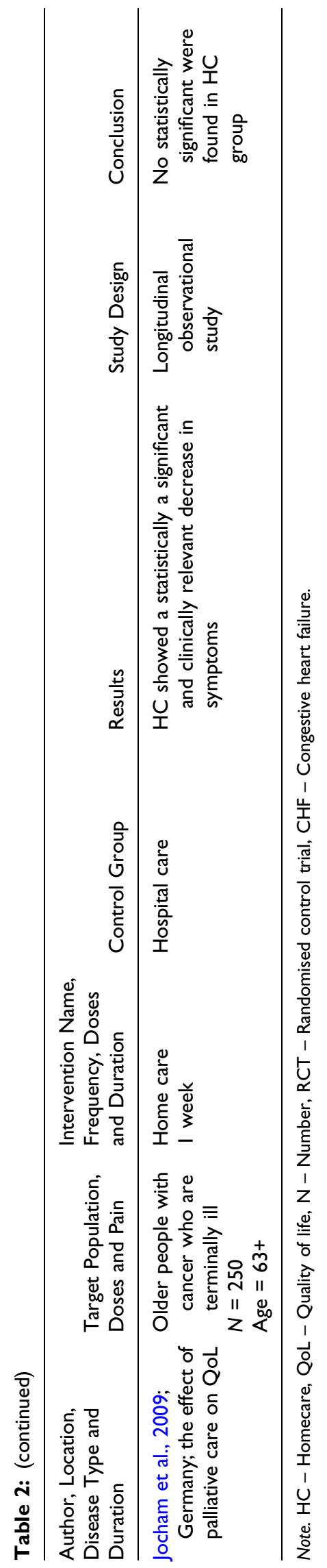




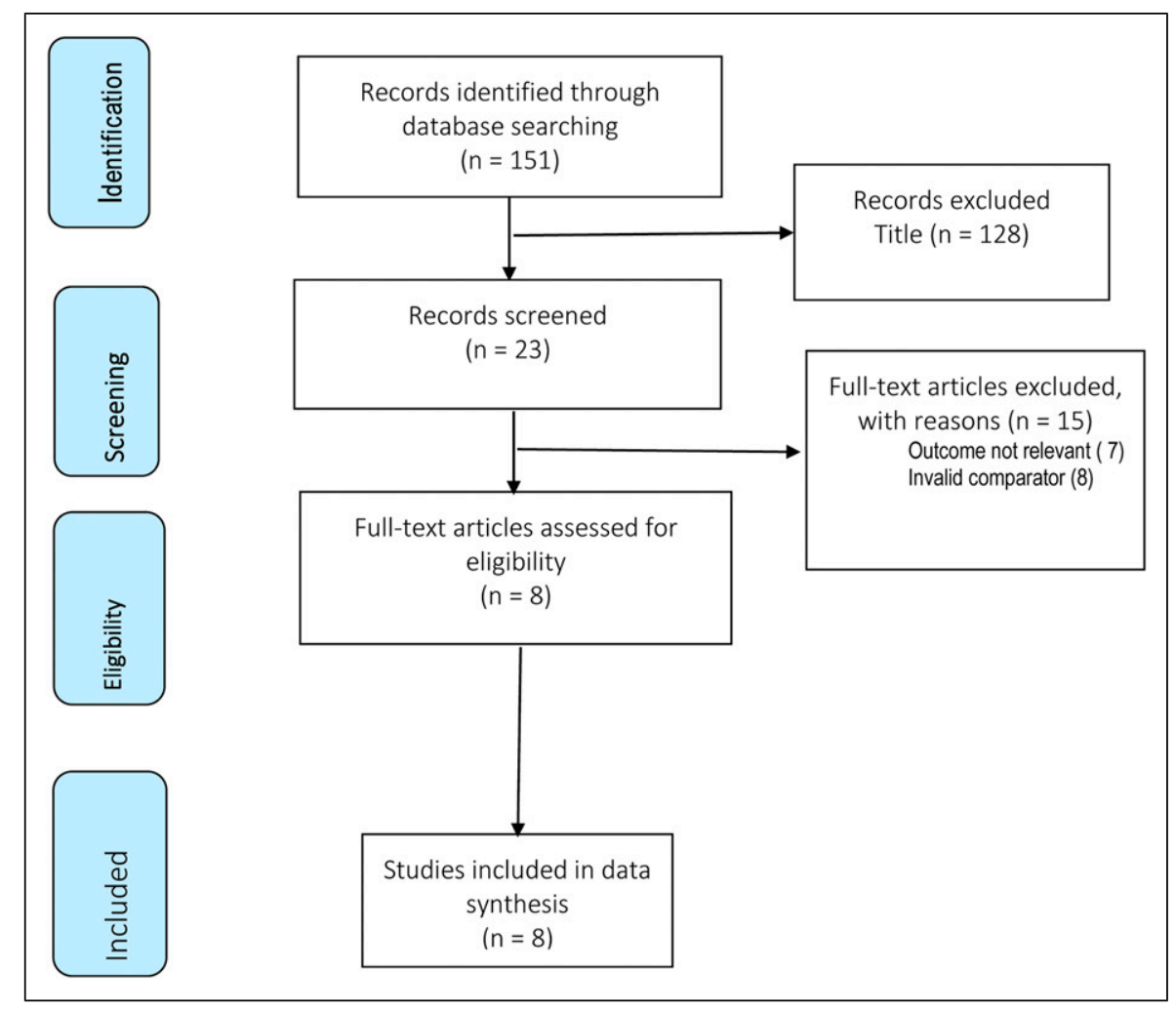

Figure I. The preferred reporting for systematic review diagram representing the systematic literature search.

could be because the personalisation was provided to older people in their own homes, and they did not have to travel or leave their homes to receive support. The support provided to older people in the community ensured that their family members are able to provide addition support as part of the personalisation process this might not have been possible if support was provided in another setting. Direct involvement of professionals could have help to ensure adherence to personalisation interventions making this may also be a reason why personalisation was more effective such as psychiatrist (Klug et al., 2010), social workers (Klug et al., 2010), podiatrist (Spink et al., 2011), Nurses (Mehralian et al., 2014; Bilgin \& Gozum, 2018), psychologist (Klug et al., 2010) and physiotherapist (Zidén et al., 2010; Aoki et al., 2015).

\section{Discussion and Application to Practice}

Our systematic review provides evidence for the effectiveness of personalisation interventions to improve the health outcomes of older people. Compared to the control, the current review revealed that personalisation interventions improved health-related quality of life, functional mobility, degree of independence, emotional cognitive functions and reduced depressions in older people. The reason behind the improved health outcome by most of the included studies could be due to the fact that home visitor may have encouraged older people to express their problems more easily compared to the controls (Van Rossum et al., 1993). On the other hand, we did not observe a significant difference in health-related quality of life among older people with cancer (Jochan et al., 2009). The observed difference in relation to this health outcome may be due to the methodology adopted in the study. Overall, it is difficult to know which part of the interventions made a difference to the health outcomes considered as the programmes in the included studies were multifaceted.

The main strength of this study was that it is the first systematic review on the effectiveness of personalisation interventions. The included studies were assessed adequate quality. The conclusions of this study are more valid than those from a single study as the conclusions were made by synthesising findings from many studies. The study showed that the quality of life of older people can improve significantly through personalisation.

Small number of studies were included in this study, including more studies might yield a different outcome. The number of participants, the length of the included studies, and many other factors can make it hard to compare the findings of two or more studies. The studies included in this review were the ones that were conducted in English language, it might be possible to get a different outcome if studies conducted in other languages were included. Based on our review, it remains unclear as to which components of personalisation was superior to others in the current study. Thus, it is important that 


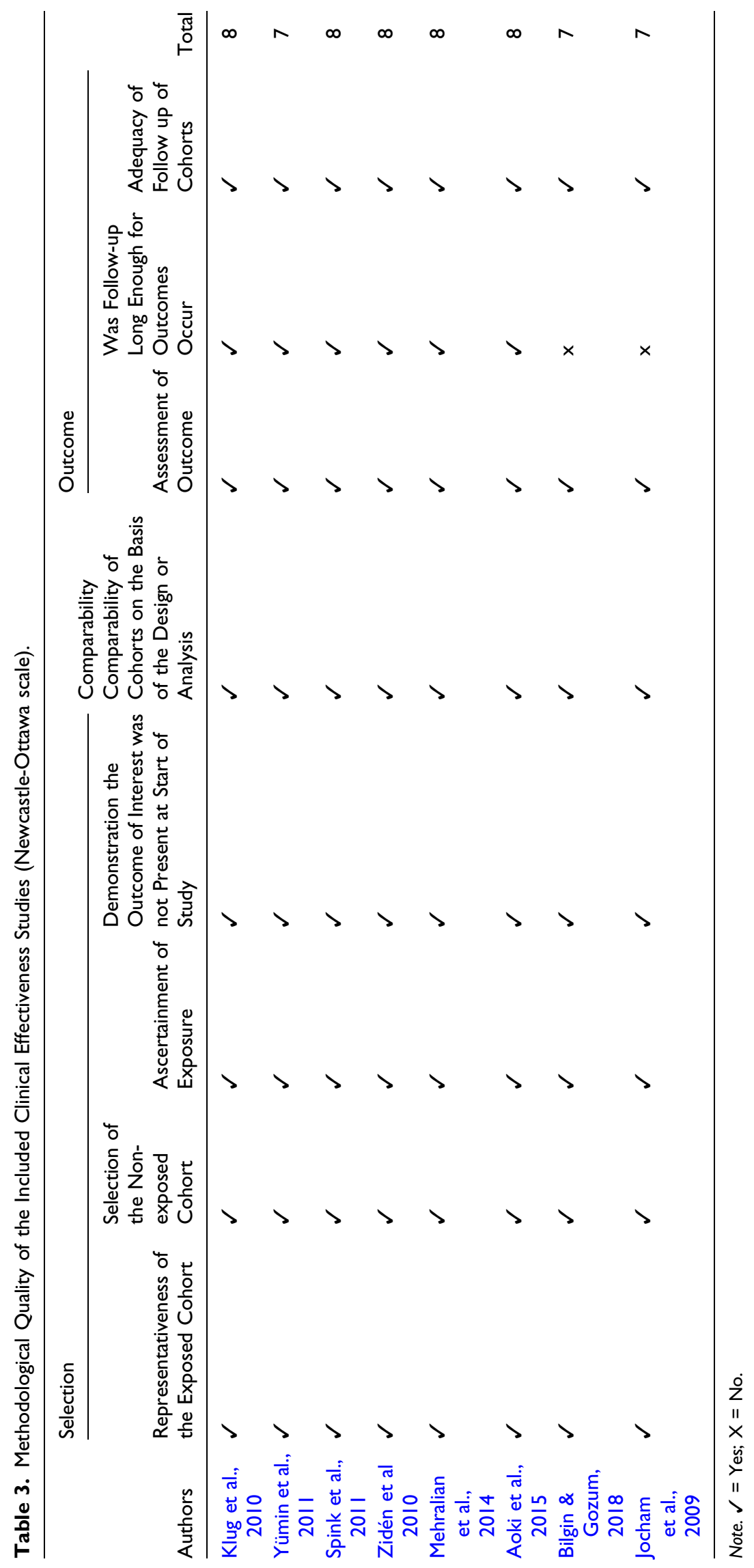


future studies are focused on implementing and evaluating which part of the programmes or interventions works best.

In conclusion, this review showed that personalisation intervention is effective compared with institutional homes such as nursing home, residential home and hospice. This is an interesting study as the studies included in this review were not limited to a particular geographical region as they were from all over the world which would make it possible to generalise the findings from these syntheses. The methodology used is clear and can be repeated. Social worker and other practitioners, decision makers and social services are to be aware of these findings as they may help to improve QoL of older people and cost saving. Future research should also be considered comparing the different types of periodisation approaches, particularly in terms of costeffectiveness.

\section{Author contributions}

All the authors made a substantial contribution to this paper.

\section{Declaration of Conflicting Interests}

The author(s) declared no potential conflicts of interest with respect to the research, authorship and/or publication of this article.

\section{Funding}

The author(s) received no financial support for the research, authorship and/or publication of this article.

\section{Ethical Approval and Dissemination}

This is a narrative synthesis study, therefore, the participants in this study were not directly involved in this study. Ethical approval was not sought for this study as it is not required. Findings from this study would be disseminated through conferences paper at conferences and peer-review journals at reputable journals.

\section{ORCID iDs}

Clara T. Fatoye (iD https://orcid.org/0000-0003-3509-5065

Tadesse Gebrye (D) https://orcid.org/0000-0001-7976-2013

\section{References}

Aoki, K, Sakuma, M, Ogisho, N, Nakamura, K, Chosa, E, \& Endo, N (2015). The effects of self-directed home exercise with serial telephone contacts on physical functions and quality of life in elderly people at high risk of locomotor dysfunction. Acta Medica Okayama, 69(4), 245-253

Bennett, K. M. (2010). "You can't spend years with someone and just cast them aside": Augmented identity in older British widows. Journal of Women \& Aging, 22(3), 204-217

P. Beresford (Ed), (2014). Personalisation. Policy Press.

Bilgin, S., \& Gozum, S. (2018). Effect of nursing care given at home on the quality of life of patients with stomach cancer and their family caregivers' nursing care. European Journal of Cancer Care, 27(2), e12567.
Cyrus, K. (2017). Multiple minorities as multiply marginalized: Applying the minority stress theory to LGBTQ people of color. Journal of Gay \& Lesbian Mental Health, 21(3), 194-202

Department of Health (2010a). Healthy lives, healthy people: Our strategy for public health in England (Vol. 7985). The Stationery Office.

Department of Health (2010b). Fairer contributions guidance: Calculating an individual's contribution to their personal budget: Department of Health.

Eurostat, A. (2017). A look at the lives of the elderly in the EU today. Feigin, V. L., Abajobir, A. A., Abate, K. H., Abd-Allah, F., Abdulle, A. M., Abera, S. F., \& Nguyen, G. (2017). Global, regional, and national burden of neurological disorders during 1990-2015: A systematic analysis for the Global Burden of Disease Study 2015. The Lancet. Neurology, 16(11), 877-897.

Foster, M., Harris, J., Jackson, K., Morgan, H., \& Glendinning, C. (2006). Personalised social care for adults with disabilities: a problematic concept for frontline practice. Health and Social Care in the Community, 14(2), 125-135.

Glasby, J., \& Dickinson, H. (2014). Partnership working in health and social care: What is integrated care and how can we deliver it? Policy Press.

Glendinning, C., Mitchell, W., \& Brooks, J. (2015). Ambiguity in Practice? Carers' roles in personalised social care in England. Health \& Social Care in the Community, 23(1), 23-32.

Irvine, F., Wah Yeung, E. Y., Partridge, M., \& Simcock, P. (2017). The impact of personalisation on people from Chinese backgrounds: Qualitative accounts of social care experience. Health \& Social Care in the Community, 25(3), 878-887.

Jocham, H. R., Dassen, T., Widdershoven, G., Middel, B., \& Halfens, R. (2009). The effect of palliative care in home care and hospital on quality of life. Journal of Hospice \& Palliative Nursing, 11(2), 119-126.

Klug, G., Hermann, G., Fuchs-Nieder, B., Panzer, M., HaiderStipacek, A., Zapotoczky, H. G., \& Priebe, S. (2010). Effectiveness of home treatment for elderly people with depression: randomised controlled trial. British Journal of Psychiatry, 197(6), 463-467.

Lakey, L., \& Saunders, T. (2011). Getting personal? Making personal budgets work for people with dementia: Alzheimer's Society.

Leadbeater, C (2004). Personalisation through participation: A new script for public services. Demos.

Lloyd, L. (2010). The individual in social care: The ethics of care and the 'personalisation Agenda' in services for older people in England. Ethics and Social Welfare, 4(2), 188-200.

W. Lutz, W. P. Butz, \& K. C. Samir (Eds), (2017). World population \& human capital in the twenty-first century: An overview. Oxford Scholarship Online.

Mehralian, H, Salehi, S, Moghaddasi, J, Amiri, M, \& Rafiei, H (2014). The comparison of the effects of education provided by nurses on the quality of life in patients with congestive heart failure $(\mathrm{CHF})$ in usual and home-visit cares in Iran. Global Journal of Health Science, 6(3), 256-260. 
Moher, D., Liberati, A., Tetzlaff, J., \& Altman, D. G., \& Prisma Group (2009). Preferred reporting items for systematic reviews and meta-analyses: The PRISMA statement. PLoS Medicine, 6(7), e1000097.

Moher, D., Shamseer, L., Shamseer, L., Clarke, M., Ghersi, D., Liberati, A., Petticrew, M., Shekelle, P., \& Stewart, L. A. (2015). Preferred reporting items for systematic review and meta-analysis protocols (PRISMA-P) 2015 statement. Systematic Reviews, 4(1), 1-9.

Nations, U. (2019). World Population Ageing 2019 Highlights. New York, NY, USA: United Nations, Department of Economic and Social Affairs.Population Division.

Prince, M. J., Wu, F., Guo, Y., Gutierrez Robledo, L. M., O’Donnell, M., Sullivan, R., \& Yusuf, S. (2015). The burden of disease in older people and implications for health policy and practice. The Lancet, 385(9967), 549-562.

Spink, MJ, Menz, HB, Fotoohabadi, MR, Wee, E, Landorf, KB, Hill, KD, \& Lord, SR (2011). Effectiveness of a multifaceted podiatry intervention to prevent falls in community dwelling older people with disabling foot pain: randomised controlled trial. $B M J$ (Clinical Research ed.), 342, d3411-34.

Van Rossum, E., Frederiks, C. M., Philipsen, H., Portengen, K., Wiskerke, J., \& Knipschild, P. (1993). Effects of preventive home visits to elderly people. Bmj: British Medical Journal, 307(6895), 27-32.

Wells, G. A., Shea, B., O’Connell, D., Peterson, J., Welch, V., Losos, M., \& Tugwell, P. (2000). The Newcastle-Ottawa Scale (NOS) for assessing the quality of nonrandomised studies in meta-analyses.

World Health Organization (2018). WHO clinical consortium on healthy ageing 2017: Focus: Development of comprehensive assessments and care plans: Report of consortium meeting, 2122 November 2017: World Health Organization. (No. WHO/ FWC/ALC/18.1).

Yümin, E. T., Şimşek, T. T., Sertel, M., Öztürk, A., \& Yümin, M. (2011). The effect of functional mobility and balance on healthrelated quality of life (HRQoL) among elderly people living at home and those living in nursing home. Archives of Gerontology and Geriatrics, 52(3), e180-e184.

Zamfir, M. (2013). Personalisation through personal budgets: its effectiveness for older adults in social care services. Findings from an English-based literature review. Research, Policy and Planning, 30(2), 77-89.

Zidén, L., Kreuter, M., \& Frändin, K. (2010). Long-term effects of home rehabilitation after hip fracture - 1-year follow-up of functioning, balance confidence, and health-related quality of life in elderly people. Disability and Rehabilitation, 32(1), 18-32. 